\title{
Genetic diversity and population structure of Peronosclerospora sorghi isolates of Sorghum in Uganda
}

\author{
Kumi Frank ${ }^{1,2 *}$, Agbahoungba Symphorien ${ }^{1}$, Badji Arfang ${ }^{1}$, Mwila Natasha ${ }^{1}$, \\ Ibanda Angele ${ }^{1}$, Anokye Michael ${ }^{2}$, Odong Thomas ${ }^{1}$, Wasswa Peter ${ }^{1}$, Ochwo- \\ Ssemakula Mildred ${ }^{1}$, Tusiime Geoffrey ${ }^{1}$, Biruma Moses ${ }^{3}$, Kassim Sadik ${ }^{4}$, and \\ Rubaihayo Patrick ${ }^{1}$
}

\footnotetext{
${ }^{1}$ Department of Agricultural Production, College of Agricultural and Environmental Sciences, Makere re University, P.O.

Box 7062, Kampala, Uganda.

${ }^{2}$ Department of Crop Science, College of Agricultural and Natural Sciences, University of Cape Coast, P.M.B Cape Coast, Ghana.

${ }^{3}$ National Semi-Arid Resources Research Institute (NaSARRI), Serere, Uganda.

${ }^{4}$ Abi-Zonal Agricultural Research and Development Institute, National Agricultural Research Organization, P. O. Box 219, Arua, Uganda.
}

Address of corresponding author: frankkumifk@gmail.com

\begin{abstract}
Sorghum is the third most important staple cereal crop in Uganda after maize and millet. Downy mildew disease is one of the most devastating fungal diseases which limits the production and productivity of the crop. The disease is caused by an obligate fungus, Peronosclerospora sorghi (Weston \& Uppal) with varying symptoms. Information on the genetic diversity and population structure of P.sorghi in sorghum is imperative for the screening and selection for resistant genotypes and further monitoring possible mutant(s) of the pathogen. Isolates of $P$. sorghi infecting sorghum are difficult to discriminate when morphological descriptors are used. The use of molecular markers is efficient, and reliably precise for characterizing $P$. sorghi isolates. This study was undertaken to assess the level of genetic diversity and population structure that exist in P. sorghi isolates in Uganda. A total of 195 P. sorghi isolates, sampled from 13 different geographic populations from 10 different regions (agro-ecological zones) was used. Eleven (11) molecular markers, comprising of four Random amplified microsatellite (RAM) and seven (7) Inter-Simple Sequence Repeat (ISSR) markers were used in this study. The analysis of molecular variation (AMOVA) based on 11 microsatellite markers showed significant $(P<0.001)$ intra-population (88.9\%, PhiPT $=0.111)$ and inter-population $(8.4 \%$, PhiPR $=0.083)$ genetic variation, while the genetic variation among regions $(2.7 \%$, PhiRT $=0.022)$ was not significant. The highest genetic similarity value $(0.987=98.7 \%)$ was recorded between Pader and Lira populations and the
\end{abstract}

lowest genetic similarity $(0.913=91.3 \%)$ was observed between Namutumba and Arua populations. The mean Nei's genetic diversity index $(H)$ and Shannon Information Index (I) were 0.308 and 0.471 respectively. Seven distinct cluster groups were formed from the $195 \mathrm{P}$. sorghi isolates based on their genetic similarity. Mantel test revealed no association between genetic differentiation and geographical distance $\left(R^{2}=0.0026, p\right.$ $=0.02$ ) within the 13 geographic populations.

Keywords- AMOVA, Genetic diversity Index, ISSR, Mantel test, RAM, Shannon Information Index.

\section{INTRODUCTION}

Downy mildew disease of sorghum, caused by an obligate soil-borne fungus Peronosclerospora sorghi (P. sorghi) [Weston and Uppal (Shaw)] (Frederiksen, 1980) poses a serious biotic stress to sorghum production and productivity worldwide (Williams, 1984). The prevalence and distribution of the disease is favoured by factors such as high relative humidity (Wang et al., 2000), low temperature (Bock et al., 1998) and rainfall which favours conidia production and subsequent development of the disease. When the disease is not managed at the early stages of infection, losses can reach $100 \%$. Infected plants show localized and systematic symptoms varying from lesions on leaf lamina to chlorosis (Jeger et al., 1998). Previous reports suggest the prevalence and distribution of Sorghum downy mildew disease (SMD) in Uganda at varying incidence and severity levels (Bigirwa et al., 1998; Kumi et al., 2018), but no study has been 
done to unravel the state of genetic diversity of $P$. sorghi is olates in Uganda.

Morphological and molecular characterizations are two methods commonly used to assess genetic variability of $P$. sorghi (Bock, 1995). Unlike molecular characterization, morphological characterization is exclusively dependant on morphological traits of $P$. sorghi which come with several shortcomings ranging from; influence by environmental factors, time consuming and lack of efficient resolution power required to discriminate between genetically related isolates. More so, the use of morphological descriptors to assess genetic variation among isolates of $P$. sorghi is reported to be limited (Bock, 1995).

The advent of molecular markers has made it easier to study genetic diversity and population structure of $P$. sorghi with much precision and better accuracy (Perumal et al., 2006). Random Amplified Polymorphic DNA (RAPD) primers, Simple Sequence Repeats (SSRs) and Amplified Fragment Length Polymorphism (AFLP) have been extensively used to explore the variability among P. sorghi isolates (Bock et al., 2000) and different pathotypes of P. sorghi in sorghum (Perumal et al., 2008). Compared to other parts of the world, pathogenic and molecular variability among the $P$. sorghi isolates of sorghum have been well documented (Bock et al. 2000; Mathiyazhagan et al., 2008). Outcome of such research confirmed the existence of genetic diversity in P. sorghi and led to identification of new pathotypes (Perumal et al., 2006).

Perumal et al. (2006) analyzed the genetic variability among the 14 isolates of $P$. sorghi including metaxyl resistant isolates and reported that approximately $25 \%$ of the bands were polymorphic across the isolates in the tested populations. Mathiyazhagan et al. (2006) also reported similar genetic variability between isolates from sorghum and corn in India, using restriction fragment length polymorphism analysis of the polymerase chain reaction (PCR). Sequence characterized amplified region
(SCAR) marker have also been used to assess genetic variability of P. sorghi (Ladhalakshmi et al, 2009).

Knowledge regarding the extent of genetic diversity and genetic relationships of P. sorghi in Uganda will be valuable for designing a comprehensive breeding strategy for identifying resistant sorghum genotypes that will be resilient to SDM disease. Thus, studying and quantifying genetic diversity of $P$. sorghi from different agro-ecologies will offer a valuable marker assisted selection and breeding strategy. The objective of this study was to characterize the isolates of $P$. sorghi in Uganda by assessing the population structure, genetic diversity and/or relatedness using ISSR and RAMS markers.

\section{METHODOLOGY}

\section{Collection of samples}

Hierarchical sampling technique was used to collect a total of 195 SDM samples from 13 districts (Table 1 and Fig 1) covering all the ten agro-ecologies in Uganda. These samples were taken from sorghum plants with leaves showing systemic and/or localized characteristic lesions of mildew with conspicuous conidia growth. Leaves samples were carefully covered with aluminum foil, labeled and stored in a cooler.

\section{DNA extraction and purification}

DNA extraction was done following the protocol described by McDermott et al. (1994). Conidia found on leaves were collected using a camel hair brush and transferred to a 1.5-ml microcentrifuge tube containing $500 \mu \mathrm{l}$ of extraction buffer $(50 \mathrm{mM}$ Tris- $\mathrm{HCl}, \mathrm{pH} 8.0$; $0.7 \mathrm{M} \mathrm{NaCl}$ and $1 \%$ SDS $)(1 \times 108$ spores $/ \mathrm{ml})$, vortexed for $30 \mathrm{~s}$ and incubated at $60{ }^{\circ} \mathrm{C}$ for $1 \mathrm{~h}$. After incubation, the mixture was centrifuged at $12,000 \times \mathrm{g}$ for $10 \mathrm{~min}$, and the aqueous phase was collected and extracted twice with an equal volume of phenol: chloroform: isoamylalcohol (25:24:1). The aqueous phase was transferred to a $1.5-\mathrm{ml}$ microcentrifuge tube and the DNA was precipitated by addition of an equal volume of cold isopropanol and incubation at $-20^{\circ} \mathrm{C}$ for $1 \mathrm{~h}$.

Table.1: Geographical and climatic data of P. sorghi populations in Uganda.

\begin{tabular}{|c|c|c|c|c|c|c|}
\hline $\begin{array}{l}\text { Populatio } \\
\mathrm{n}\end{array}$ & Latitude & Longitude & $\begin{array}{l}\text { Altitude } \\
\text { (m) }\end{array}$ & $\begin{array}{l}\text { Ave. } \\
\text { Temp } \\
\left({ }^{\circ} \mathrm{C}\right)\end{array}$ & $\begin{array}{c}\text { Annual } \\
\text { Rainfall } \\
(\mathrm{mm})\end{array}$ & Agro-ecological zone \\
\hline Iganga & $\mathrm{N}^{\circ} 0^{\circ} 37.402^{\prime}$ & $\mathrm{E} 033^{\circ} 29.657^{\prime}$ & 1022 & 22.3 & 1313 & Lake Victoria Crescent \\
\hline Namutum & & & & 23.4 & 1011 & Lake Victoria Crescent \\
\hline ba & N00 $48.309^{\prime}$ & $\mathrm{E} 033^{\circ} 39.273^{\prime}$ & 1091 & & & \\
\hline Pallis a & N00 $48.309^{\prime}$ & $\mathrm{E} 033^{\circ} 39.273^{\prime}$ & 1081 & 23.2 & 1353 & Lake Kyoga Basin \\
\hline Kumi & $\mathrm{N}^{\circ} 1^{\circ} 16.556^{\prime}$ & $\mathrm{E} 033^{\circ} 52.238^{\prime}$ & 1125 & 23.2 & 1238 & Lake Kyoga Basin \\
\hline Serere & N0131.167' & $\mathrm{E} 033^{\circ} 33.089^{\prime}$ & 1104 & 23.8 & 1362 & Eastern Highlands \\
\hline Lira & N00 $18.478^{\prime}$ & $\mathrm{E} 032^{\circ} 34.292^{\prime}$ & 1153 & 23.6 & 1219 & Northern Grassland \\
\hline
\end{tabular}




\begin{tabular}{|c|c|c|c|c|c|c|}
\hline Pader & N02 ${ }^{\circ} 48.549^{\prime}$ & $\mathrm{E} 033^{\circ} 06.440^{\prime}$ & 979 & 23.7 & 1239 & Northern Grassland \\
\hline Hoima & $\mathrm{N}^{\circ} 1^{\circ} 26.270^{\prime}$ & $\mathrm{E} 031^{\circ} 21.541^{\prime}$ & 1113 & 22.6 & 1382 & Western Mid-Altitude \\
\hline Masindi & N01 ${ }^{\circ} 40.888^{\prime}$ & $\mathrm{E} 031^{\circ} 43.540^{\prime}$ & 1194 & 22.9 & 1355 & Lake Albert Crescent \\
\hline Arua & N03 $01.303^{\prime}$ & $\mathrm{E} 030^{\circ} 54.684^{\prime}$ & 1109 & 22.9 & 1404 & West Nile \\
\hline Nebbi & $\mathrm{N} 02^{\circ} 32.943^{\prime}$ & $\mathrm{E} 031^{\circ} 06.064^{\prime}$ & 1061 & 23.2 & 1098 & Northwestern Grass land \\
\hline Kabarole & $\mathrm{N}^{\prime} 00^{\circ} 36.511^{\prime}$ & $\mathrm{E} 030^{\circ} 15.428^{\prime}$ & 1106 & 19.3 & 1459 & $\begin{array}{l}\text { Western Mid-High } \\
\text { Altitude }\end{array}$ \\
\hline Kabale & $\mathrm{S} 01^{\circ} 15.660^{\prime}$ & $\mathrm{E} 030^{\circ} 01.444^{\prime}$ & 1934 & 17.2 & 1018 & Southwestern Highlands \\
\hline
\end{tabular}

Source: Field data, 2016.

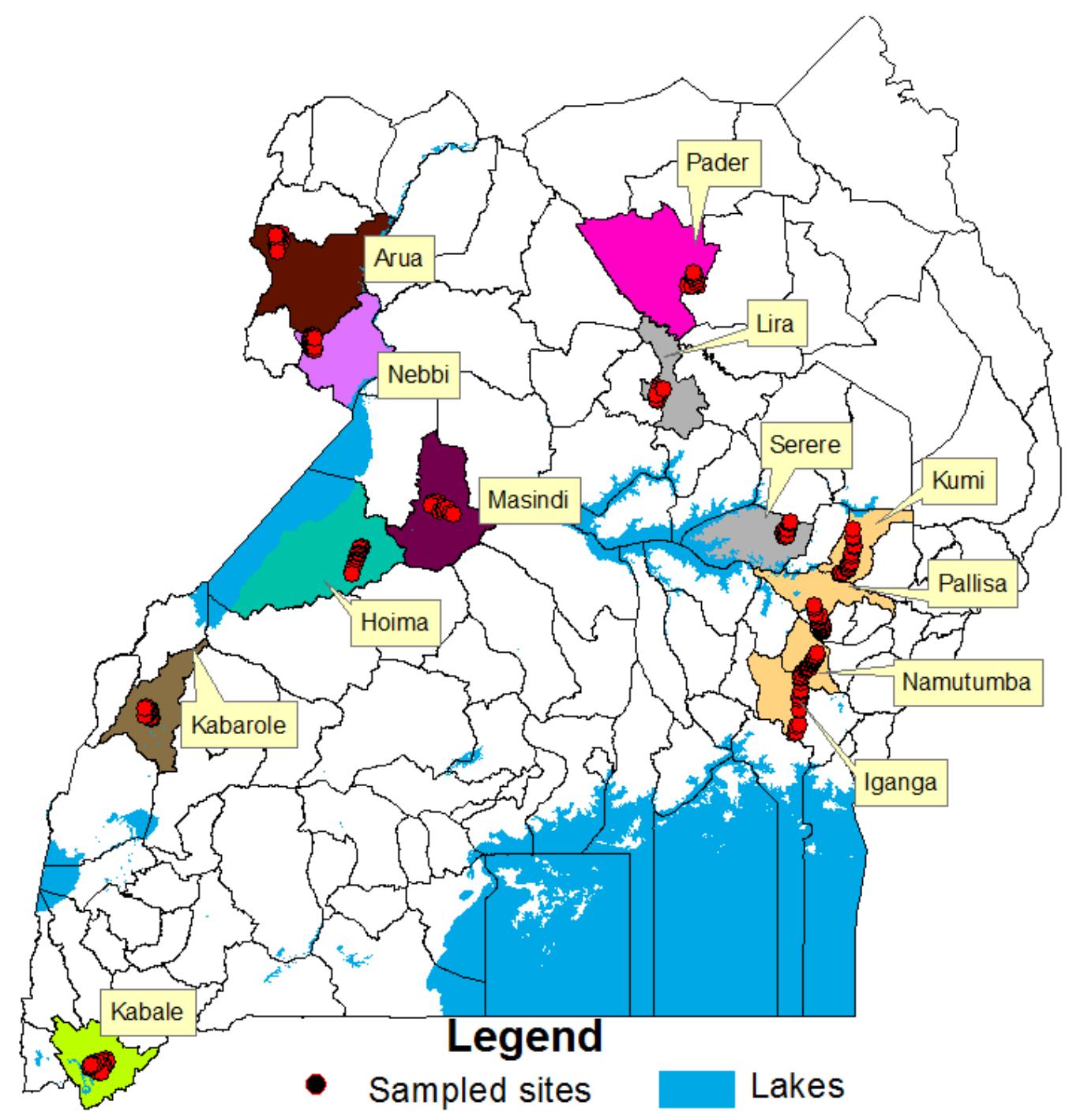

Fig. 1: Sampling sites of Peronosclerospora sorghi for the study. The small circled marks in each population (District) are the precised sampling points.

The DNA was pelleted by centrifugation at $12,000 \times \mathrm{g}$ at $4^{\circ} \mathrm{C}$ for $10 \mathrm{~min}$. The pellet was washed twice with cold $70 \%$ ethanol, air-dried and re-suspended in $50 \mu \mathrm{l}$ of TrisEDTA buffer (10 mM Tris- $\mathrm{HCl}$ and $1 \mathrm{mM}$ EDTA, $\mathrm{pH}$ 8.0). The genomic DNA was checked by agarose gel electrophoresis and the concentrations of the DNA were determined using a NanoDrop spectrometer nm (Thermo Scientific, Waltham, MA) by measuring the absorbance at 260.

Amplification and electrophoresis 
A total of twenty (20) primers, consisting of nine (9) Random Amplified Microsatellites (RAMS) and eleven (11) Inter Simple Single Repeats (ISSRs) (Table 2) were used to screen the 195 P. sorghi isolates, but eleven (11) primers yielded clear visible PCR products and those were used in this study.

Table.2: List of Primers used in this study

\begin{tabular}{|c|c|c|c|}
\hline Primer & Primer sequence $\left(5^{\prime}-3^{\prime}\right)$ & Length & AT $\left({ }^{\circ} \mathbf{C}\right)$ \\
\hline UBC $809^{\mathrm{a}}$ & AGAGAGAGA GA GA GA GG & 17 & 50 \\
\hline $\mathrm{UBC} 824^{\mathrm{a}}$ & ТСТСТСТСТСТСТСТСG & 17 & 47 \\
\hline $\mathrm{UBC} 825^{\mathrm{a}}$ & ACACACACACACACACT & 17 & 50 \\
\hline UBC826 & ACACACACACACACACC & 17 & 47 \\
\hline UBC836a & AGAGAGAGA GA GA GA GYA & 18 & 50 \\
\hline $\mathrm{UBC} 841^{\mathrm{a}}$ & GAGAGAGA GA GA GA GATC & 18 & 47 \\
\hline $\mathrm{UBC} 842^{\mathrm{a}}$ & GAGAGAGA GA GA GA GA & 16 & 45 \\
\hline UBC847 & CACACACACACACACAAC & 18 & 47 \\
\hline UBC848 & CACACACACACACACACG & 18 & 45 \\
\hline UBC849 & СТСТСТСТСТСТСТСТСА & 18 & 47 \\
\hline UBC $880^{\mathrm{a}}$ & GGA GA GGA GA GGA GA & 15 & 47 \\
\hline RAMS1 ${ }^{\mathrm{a}}$ & CACACAACAACAACAACA & 18 & 45 \\
\hline RAMS2a & GACCACCACCACCACCA & 17 & 55 \\
\hline RAMS3 a & ATCCGACGA CGACGACGA & 18 & 50 \\
\hline RAMS4 & AGGGT GT GT GT GTG & 14 & 45 \\
\hline RAMS5 & AACACACACACA & 12 & 35 \\
\hline RAMS6 $^{\mathbf{a}}$ & ACCAGAGAGA GA G & 13 & 40 \\
\hline RAMS7 & GCATATATATATGT & 14 & 35 \\
\hline RAMS8 & CTAGAGAGA GCTCTG & 15 & 45 \\
\hline RAMS9 & GATCGCGCGCGCGTC & 15 & 55 \\
\hline
\end{tabular}

$\mathrm{a}=$ Primers which yielded visible polymorphic bands.

These primers have the ability to differentiate among is olates of $P$. sorghi. Each PCR reaction $(20 \mu \mathrm{l})$ contained $50 \mathrm{ng}$ of genomic DNA as template, $5 \mathrm{mM}$ each dNTPs, 10 pmol of primer and $0.5 \mu \mathrm{l}$ of Taq DNA polymerase. DNA Amplification was performed using the following thermal cycle parameters; $94{ }^{\circ} \mathrm{C}$ for $5 \mathrm{~min}$, followed by 30 cycles of $94{ }^{\circ} \mathrm{C}$ for $1 \mathrm{~min}, 37^{\circ} \mathrm{C}$ for $1 \mathrm{~min}$, and $72^{\circ} \mathrm{C}$ for $1 \mathrm{~min}$ and a final extension at $72{ }^{\circ} \mathrm{C}$ for $10 \mathrm{~min}$ at the end of amplification. The PCR products were analyzed by electrophoresis on a $1.5 \%(\mathrm{w} / \mathrm{v})$ agarose gel containing $0.5 \mu \mathrm{g} / \mathrm{ml}$ of ethidium bromide in Tris-acetate-EDTA (TAE) buffer (0.04 M Tris-acetate, $0.001 \mathrm{M}$ EDTA, pH
8.0) and subsequently visualized under UV light. Selected ISSRs and RAMs amplifications were further repeated to ensure reproducibility. Polymorphic bands were subsequently screened with a 100 base pair (bp) marker.

Data collection and analyses

Data collected from the amplified multiloci bands which were clearly visible were scored manually for each isolate using a binary format according to presence (1) or absence (0) (Santacruz-Varela et al., 2013) from the image of ethidium bromide stained gels (Fig. 2) of the target isolates. 


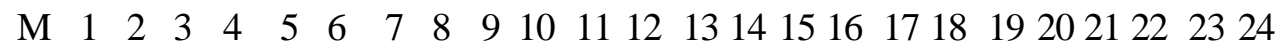

$\mathbf{a}$

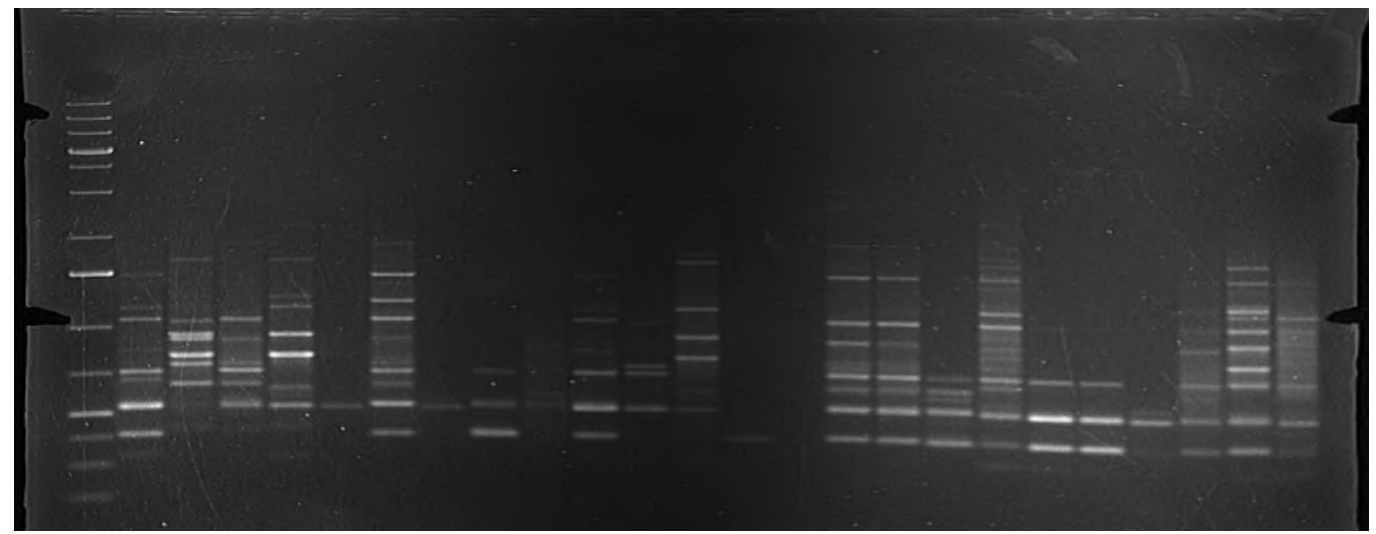

$\begin{array}{llllllllllllllll}M & 1 & 2 & 3 & 4 & 5 & 6 & 7 & 8 & 9 & 10 & 11 & 12 & 13 & 14 & 15\end{array}$

b

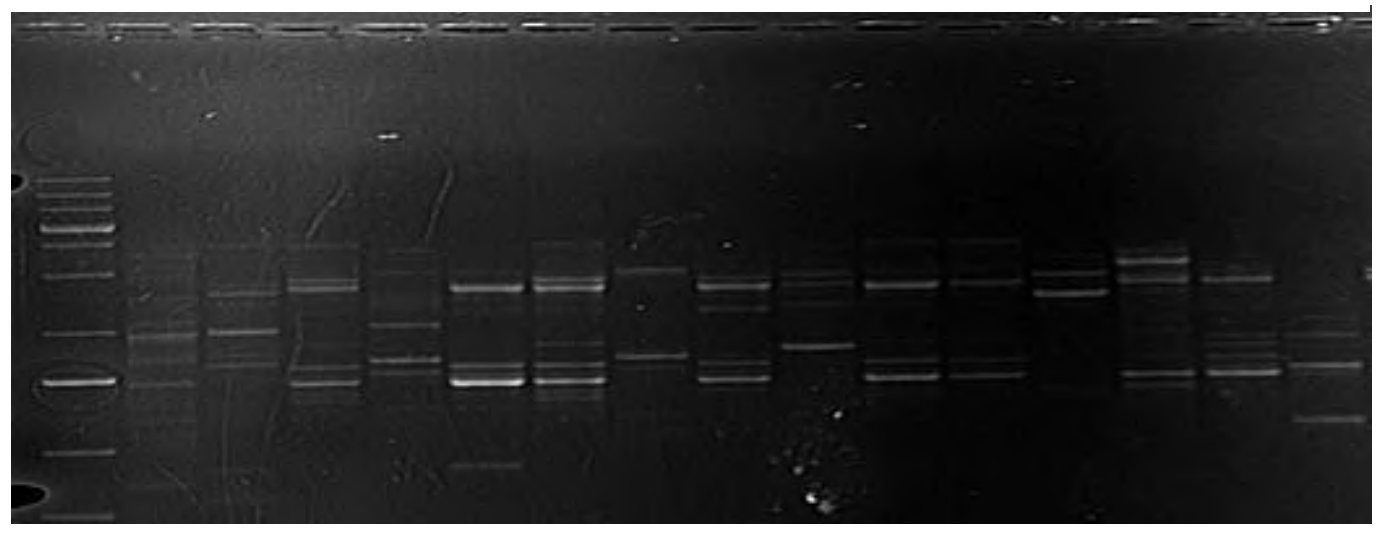

Fig. 2 Agarose gel electrophoresis of PCR amplified products from genomic DNA of P. sorghi using UBC 880 primer (ISSR primer) (a) Lane 1 (M) in both figure are 100 bp DNA ladder; Lane $2-24$ ( P. sorghi Isolates, Lane 14 is an empty well) and RAMS 3 (RAMS primer) (b) Lane $2-16$ (P. sorghi Isolates).

The binary data were subjected to analysis of molecular variance (AMOVA) ( Reyes-Valdés et al., 2013; Excoffier et al., 1992) with 999 permutations using GenAlEx6.5 (Peakall \& Smouse, 2006; 2012). The total genetic variation among 195 isolates was generated using phi-statistic through AMOVA. The genetic variations were partitioned into three; variation among regions (PhiRT), variation among population (PhiPR) and variation within population (PhiPT).

PhiPT coefficient values denote the proportion of estimate variance among population relative to the total variance and the pairwise between populations expressed as $\mathrm{PhiPT}=\left(\mathrm{V}_{\mathrm{AP}}+\mathrm{V}_{\mathrm{AR}} /\left(\mathrm{V}_{\mathrm{WP}}+\mathrm{V}_{\mathrm{AP}}\right)\right.$, where $\mathrm{V}_{\mathrm{AP}}$ is the estimate of variance among populations, $\mathrm{V}_{\mathrm{AR}}$ is the estimate of variance between the geographical regions, and $V_{W P}$ is the estimate of variance within the studied population. PhiPT was used to determine the genetic differentiation between the population, it is a measure which allows intra-individual variation suppression when comparing binary and codominant data (Teixeira et al., 2014).

The genetic variability of the populations (districts) was analyzed using the Hardy-Weinberg equilibrium (HWE) (Crow et al., 2008) assumption in GenAlEx 6.5 (Peakall \& Smouse, 2006; 2012). Pairwise Nei's genetic distances (Nei, 1972) and Pairwise Nei's genetic identity between geographical populations of $P$. sorghi were obtained based on 999 permutations. The percentage of polymorphic loci (PPL), number of bands (No. Bands), number of different alleles (Na), number of effective alleles (Ne), Shannon Information Index (I), expected heterozygosity/ Genetic Diversity Index $(\mathrm{H})$ and unbiased expected heterozygosity (uHe). The Shannon diversity index $(I)$ is an index that is commonly used to characterize species diversity in a giving population. Shannon's index $(H)$ accounts for both abundance and evenness of the species present and expressed as a proportion of species $i$ relative to the total number of species $\left(p_{i}\right)$, and then multiplied by the natural logarithm of this proportion $\left(\ln p_{i}\right)$. The resulting product is summed across species, and multiplied by -1 .

$H=\sum_{i=1}^{s}-(p i * \ln p i)$ (Spellerberg \& Fedor, 2003)

Data on latitudinal and longitudinal coordinate for each isolate was converted into decimal degrees to 
estimate geographical distance matrix. Similarly, genetic distance was obtained by transforming the binary binary data ( 0 for absence and 1 for presence of amplicon) from the ISSR and RAMS amplified product. Mantel Test with 999 permutation was computed in GenAlEx to examine whether populations (districts) that are geographically close are also genetically similar.

Mantel test in GenAlEx (Peakall \& Smouse, 2006; 2012) was performed to examine whether genetic isolation was associated with the geographic distance among $P$. sorghi populations. The pairwise Nei's population genetic distances were calculated based on gene frequency differences between populations, and these distances were then compared to geographic distances between populations and a correlation was run for these two parameters. The genetic distance matrix generated from 195 isolates in GenAlEx was used to perform a hierarchical cluster analysis based on Ward's hierarchical agglomerative clustering method (Ward, 1963) using R statistical package (R Core Team, 2013). A cluster dendogram was generated for the isolates (Maechler et al., 2016). In other to determine the optimal number of clusters for the dendogram, the Bayesian Inference Criterion (BIC) (Akogul, 2017) for $\mathrm{k}$ means method was used. This method deploys expectationmaximization, initialized by hierarchical clustering for parameterized Gaussian mixture models (Reynolds, 1992).

Following the cluster analysis, Discriminant Analysis of Principal Components (DAPC) (Jombart et al., 2010) was carried out in $\mathrm{R}$ statistical package to assess the relationships between the different clusters, using a method that focus on variability between-group, while neglecting variability within-group variation, which is precisely the rationale of Discriminant Analysis (DA) (Lachenbruch \& Goldstein, 1979) to achieve the best discrimination of isolates into pre-defined groups. DAPC scatter-plot was generated which allows for a graphical assessment of the genetic structures between clusters.

\section{RESULTS}

Genetic variation and relationship in $P$. sorghi at varied population levels

Statistical analyses which were performed on the total of 120 amplified polymorphic loci from PCR reaction for $P$. sorghi isolates using ISSR and RAMS revealed a wide genetic diversity and structure in the population. The overall genetic differentiation was examined for the $195 \mathrm{P}$. sorghi isolates from 13 geographic populations (Districts) covering 10 regions (AEZ) in Uganda (Table 3). The AMOVA results are presented below.

Table.3: Analysis of molecular variance (AMOVA) showing the partitioning of genetic variation within and among populations of Peronosclerospora sorghi

\begin{tabular}{|c|c|c|c|c|c|c|c|}
\hline $\begin{array}{l}\text { Sources } \\
\text { variation }\end{array}$ & of $\mathrm{df}$ & MS & $\begin{array}{l}\text { Est. } \\
\text { variance }\end{array}$ & $\begin{array}{l}\% \text { Total } \\
\text { variation }\end{array}$ & $\begin{array}{l}\text { Phi } \\
\text { Statistic }\end{array}$ & Value & $P$ value \\
\hline $\begin{array}{l}\text { Among } \\
\text { regions }\end{array}$ & 9 & 63.519 & 1.102 & 2.7 & PhiRT & $0.022^{\mathrm{NS}}$ & 0.487 \\
\hline $\begin{array}{l}\text { Among } \\
\text { population }\end{array}$ & 3 & 44.100 & 3.368 & 8.4 & PhiPR & $0.083 * * *$ & 0.001 \\
\hline $\begin{array}{l}\text { Within } \\
\text { population }\end{array}$ & 182 & 22.468 & 35.876 & 88.9 & PhiPT & $0.111 * * *$ & 0.001 \\
\hline Total & 194 & & 40.346 & 100 & & & \\
\hline
\end{tabular}

$\mathrm{Df}=$ degree of freedom, $\mathrm{SS}=$ sum of square, Phi statistic, $P$ value is based 999 permutation. $* * *=$ Significant at $\mathrm{P}<0.001$

Partitioning of genetic differentiation at three levels (among population, within population and among regions) contributed varying degrees of genetic variation to the total variation observed. Genetic variation among and within population of the 195 isolates examined by AMOVA were significant $(\mathrm{P}<0.001)$, while genetic variation of isolates among regions where not significant. Variation within population accounted for $88.9 \%$ of the total genetic variance observed in P. sorghi isolates, this means the highest genetic diversity of these isolates occurred within population level. Variation among population and regions contributed $8.4 \%$ and $2.7 \%$ genetic variation respectively to the total diversity of $P$. sorghi. Additionally, significant $(\mathrm{P}<0.001)$ Phi values for genetic diversity were recorded among population (PhiPR $=0.083)$ and within population $(\mathrm{PhiPT}=0.111)$ while the Phi value recorded among regions $($ PhiRT $=0.022)$ was not significant.

The results from the analysis of genetic diversity among 195 isolates of $P$. sorghi from13 different populations are presented in Table 4. 
Table.4: Estimated Heterozygosity, number of bands and percentage polymorphism loci by Population

\begin{tabular}{|c|c|c|c|c|c|c|c|}
\hline Population & NPL & PPL (\%) & $\mathbf{N a}$ & $\mathrm{Ne}$ & $I$ & $\mathbf{H}$ & uHe \\
\hline Kabarole & 107 & $89.17 \%$ & $1.783(0.057)$ & 1.462 & 0.436 & 0.285 & 0.294 \\
\hline Arua & 117 & $96.67 \%$ & $1.942(0.030)$ & 1.564 & 0.493 & 0.329 & 0.341 \\
\hline Nebbi & 105 & $87.50 \%$ & $1.750(0.061)$ & 1.378 & 0.381 & 0.243 & 0.251 \\
\hline Iganga & 109 & $90.83 \%$ & $1.817(0.053)$ & 1.444 & 0.437 & 0.282 & 0.292 \\
\hline Namutumba & 105 & $87.50 \%$ & $1.750(0.061)$ & 1.559 & 0.488 & 0.329 & 0.340 \\
\hline Pallis a & 113 & $94.17 \%$ & $1.883(0.043)$ & 1.433 & 0.436 & 0.279 & 0.289 \\
\hline Kumi & 116 & $96.67 \%$ & $1.933(0.033)$ & 1.502 & 0.485 & 0.316 & 0.327 \\
\hline Kabale & 112 & $93.33 \%$ & $1.867(0.046)$ & 1.470 & 0.464 & 0.300 & 0.311 \\
\hline Hoima & 112 & $93.33 \%$ & $1.867(0.046)$ & 1.599 & 0.525 & 0.354 & 0.366 \\
\hline Masindi & 116 & $96.67 \%$ & $1.933(0.033)$ & 1.481 & 0.476 & 0.308 & 0.319 \\
\hline Lira & 119 & $99.17 \%$ & $1.983(0.017)$ & 1.490 & 0.483 & 0.312 & 0.323 \\
\hline Pader & 119 & $99.17 \%$ & $1.983(0.017)$ & 1.518 & 0.503 & 0.328 & 0.339 \\
\hline Serere & 118 & $98.33 \%$ & $1.967(0.023)$ & 1.543 & 0.515 & 0.339 & 0.350 \\
\hline Mean & 113 & $94.04 \%$ & 1.881 & 1.496 & 0.471 & 0.308 & 0.319 \\
\hline Mean SE & & $1.17 \%$ & 0.012 & 0.007 & 0.005 & 0.003 & 0.004 \\
\hline
\end{tabular}

PPL $=$ Percentage of Polymorphic loci, NPL $=$ Number of polymorphic loci, $\mathrm{Na}=$ Number of different Alleles, $\mathrm{Ne}=\mathrm{Numb}$ er of Effective Alleles, I= Shannon's Information Index, $\mathrm{H}=$ Expected Heterozygosity/ Genetic diversity index, $\mathrm{uHe}=$ Unbiased Expected Heterozygosity. Values in parenthesis are standard errors.

The mean number of different polymorphic loci, percentage of polymorphic loci, number of different Alleles, number of effective alleles, Shannon's Information Index, Nei's genetic diversity index/expected heterozygosity (measure the number of alleles and their abundance) and unbiased expected heterozygosity were 113, $94.04 \%, 1.881,1.496,0.471,0.308$ and 0.319 , respectively. The results from the analyses revealed high levels of genetic variations within population.

The percentage of polymorphic bands was high in all the 13 distinct populations, with values ranging from $87.50 \%$ for both Nebbi and Namutumba to $99.17 \%$ also for both Lira and Pader. The number of different alleles ranged from a minimum of 1.750 recorded for population in Nebbi to a maximum of 1.983 for both Lira and Pader. The number of effective alleles ranged from a minimum of 1.378 for Nebbi population to a maximum of 1.599 for Hoima. Shannon Index was highest for Serere population (0.515) and lowest at Nebbi (0.381). The results show a low genetic diversity index $(\mathrm{He})$ ranging from 0.243 for Nebbi population and 0.345 for Hoima population with an overall mean of 0.308 .

\section{Relationship for genetic distance and geographical distribution}

The results of pairwise Nei's genetic distance between geographical population of $P$. sorghi (above diagonal) and pairwise Nei's genetic similarity between geographical populations of P. sorghi (below diagonal) are presented in Table 5. The general Nei's genetic distance (genetic difference) values recorded between the tested populations of $P$. sorghi were very low, ranging from a minimum of 0.014 to maximum of 0.091 . The smallest genetic distance was observed between Lira and Pader population (0.14), both of which are in the same agro-ecological zone (Northern grassland), while the largest genetic distance was observed between Arua and Namutumba population in which fall within West Nile and Lake Victoria Crescent ecological zones respectively. The entire population of $P$. sorghi isolates recorded high genetic similarity values ranging from $0.913(91.3 \%)$ to $0.987(98.7 \%)$. The minimum genetic similarity value of $91.3 \%$ was recorded between Namutumba and Arua populations while the highest genetic similarity value of $98.7 \%$ was recorded between Pader and Lira population. 
Table.5: Pairwise Nei's genetic distances between geographical population of P. sorghi (above diagonal). Pairwise Nei's genetic similarity between geographical population of $P$. sorghi (below diagonal)

\begin{tabular}{|c|c|c|c|c|c|c|c|c|c|c|c|c|c|}
\hline $\begin{array}{l}\text { Populati } \\
\text { on }\end{array}$ & $\begin{array}{c}\text { Kabar } \\
\text { ole }\end{array}$ & $\begin{array}{c}\text { Aru } \\
\mathbf{a}\end{array}$ & $\begin{array}{c}\text { Neb } \\
\text { bi }\end{array}$ & $\begin{array}{l}\text { Igan } \\
\text { ga }\end{array}$ & $\begin{array}{c}\text { Namutum } \\
\text { ba }\end{array}$ & $\begin{array}{c}\text { Palli } \\
\text { sa }\end{array}$ & $\begin{array}{l}\text { Ku } \\
\text { mi }\end{array}$ & $\begin{array}{c}\text { Kaba } \\
\text { le }\end{array}$ & $\begin{array}{l}\text { Hoi } \\
\text { ma }\end{array}$ & $\begin{array}{c}\text { Masin } \\
\text { di }\end{array}$ & $\begin{array}{c}\text { Lir } \\
\text { a }\end{array}$ & $\begin{array}{l}\text { Pad } \\
\text { er }\end{array}$ & $\begin{array}{r}\text { Sere } \\
\text { re }\end{array}$ \\
\hline & & 0.07 & 0.04 & & & & 0.03 & & & & 0.03 & 0.03 & 0.03 \\
\hline \multirow[t]{2}{*}{ Kabarole } & - & 4 & 5 & 0.035 & 0.065 & 0.045 & 9 & 0.030 & 0.033 & 0.032 & 6 & 8 & 9 \\
\hline & & & 0.08 & & & & 0.06 & & & & 0.07 & 0.06 & 0.06 \\
\hline \multirow[t]{2}{*}{ Arua } & 0.929 & - & 8 & 0.071 & 0.091 & 0.086 & 5 & 0.068 & 0.059 & 0.072 & 4 & 7 & 9 \\
\hline & & 0.91 & & & & & 0.03 & & & & 0.03 & 0.04 & 0.03 \\
\hline \multirow[t]{2}{*}{ Nebbi } & 0.956 & 6 & - & 0.036 & 0.062 & 0.027 & 3 & 0.034 & 0.064 & 0.033 & 5 & 0 & 6 \\
\hline & & 0.93 & 0.96 & & & & 0.03 & & & & 0.03 & 0.03 & 0.03 \\
\hline Iganga & 0.965 & 1 & 5 & - & 0.057 & 0.040 & 0 & 0.031 & 0.048 & 0.030 & 1 & 0 & 1 \\
\hline Namutu & & 0.91 & 0.94 & & & & 0.07 & & & & 0.08 & 0.06 & 0.06 \\
\hline \multirow[t]{2}{*}{$\mathrm{mba}$} & 0.937 & 3 & 0 & 0.945 & - & 0.077 & 2 & 0.072 & 0.074 & 0.072 & 2 & 9 & 9 \\
\hline & & 0.91 & 0.97 & & & & 0.03 & & & & 0.02 & 0.02 & 0.02 \\
\hline \multirow[t]{2}{*}{ Pallisa } & 0.956 & 8 & 4 & 0.961 & 0.926 & - & 0 & 0.031 & 0.050 & 0.027 & 2 & 6 & 4 \\
\hline & & 0.93 & 0.96 & & & & & & & & 0.02 & 0.02 & 0.01 \\
\hline \multirow[t]{2}{*}{ Kumi } & 0.962 & 7 & 7 & 0.971 & 0.931 & 0.970 & - & 0.016 & 0.045 & 0.017 & 2 & 2 & 9 \\
\hline & & 0.93 & 0.96 & & & & 0.98 & & & & 0.02 & 0.01 & 0.02 \\
\hline \multirow[t]{2}{*}{ Kabale } & 0.970 & 5 & 7 & 0.969 & 0.930 & 0.970 & 5 & - & 0.047 & 0.016 & 1 & 9 & 2 \\
\hline & & 0.94 & 0.93 & & & & 0.95 & & & & 0.04 & 0.04 & 0.03 \\
\hline \multirow[t]{2}{*}{ Hoima } & 0.967 & 3 & 8 & 0.953 & 0.929 & 0.952 & 6 & 0.954 & - & 0.040 & 2 & 1 & 7 \\
\hline & & 0.93 & 0.96 & & & & 0.98 & & & & 0.01 & 0.01 & 0.01 \\
\hline \multirow[t]{2}{*}{ Masindi } & 0.968 & 0 & 7 & 0.970 & 0.930 & 0.974 & 4 & 0.984 & 0.961 & - & 8 & 9 & 8 \\
\hline & & 0.92 & 0.96 & & & & 0.97 & & & & & 0.01 & 0.01 \\
\hline \multirow[t]{2}{*}{ Lira } & 0.964 & 9 & 6 & 0.970 & 0.921 & 0.978 & 8 & 0.979 & 0.959 & 0.982 & - & 4 & 5 \\
\hline & & 0.93 & 0.96 & & & & 0.97 & & & & 0.98 & & 0.01 \\
\hline \multirow[t]{2}{*}{ Pader } & 0.963 & 5 & 0 & 0.970 & 0.934 & 0.974 & 9 & 0.981 & 0.960 & 0.981 & 7 & - & 6 \\
\hline & & 0.93 & 0.96 & & & & 0.98 & & & & 0.98 & 0.98 & \\
\hline Serere & 0.962 & 3 & 5 & 0.970 & 0.933 & 0.976 & 1 & 0.978 & 0.963 & 0.982 & 5 & 4 & - \\
\hline
\end{tabular}

The results from Mantel test to examine whether genetic distance was associated with geographic distance among P. sorghi populations revealed no association ( $\mathrm{Fig} 4 . \mathrm{R}^{2}=0.0026, p=0.02$ ).

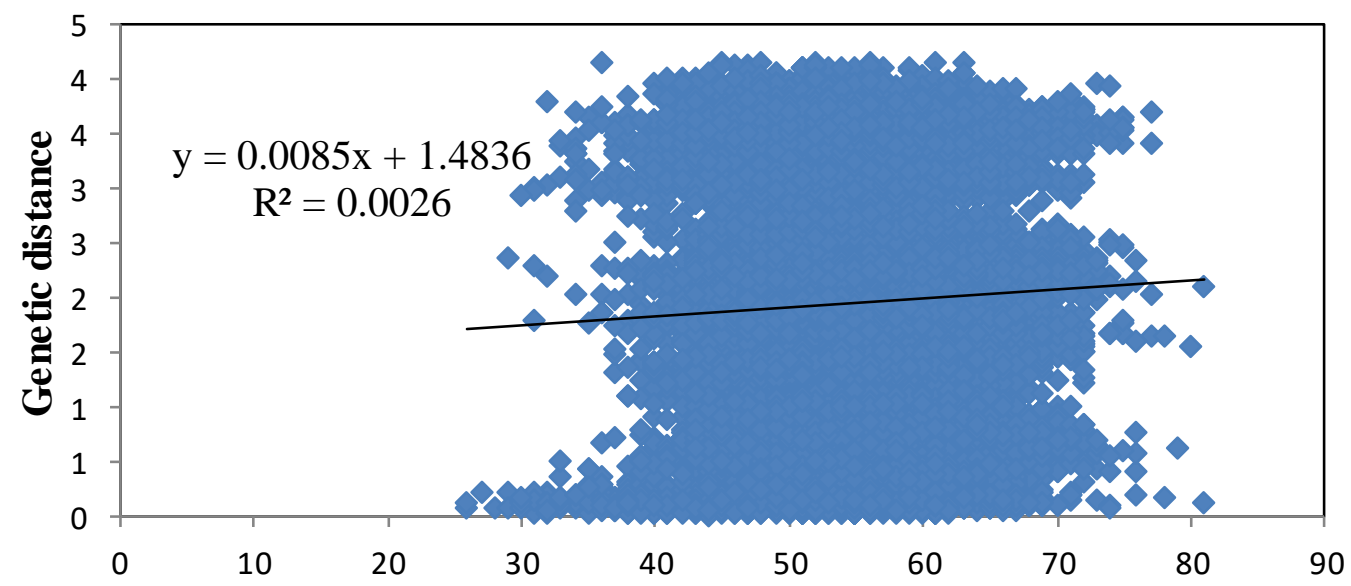

Geographic Distance

Fig. 4: Mantel test between Nei's genetic distance and geographic distance for 13 populations of P. sorghi $(\boldsymbol{r}=\mathbf{0 . 0 1 4}$.)

Cluster analysis

The 195 P. sorghi isolates from 13 different geographic populations clustered into seven distinct cluster groups (Fig. 4) which indicates genetic diversity within the population. Each cluster was mutually exclusive of isolates identity but not in geographical 
population of the isolates. The largest cluster was cluster 2 with a total of 64 isolates from 10 different geographic populations namely; Kabarole, Nebbi, Iganga, Pallisa, Kumi, Kabale, Masindi, Lira, Pader and Serere. The least weighted cluster was cluster 3 with 10 isolates from two geographic populations namely, Kabarole and Hoima. The remaining clusters, cluster $1,4,5,6$, and 7 constituted a total of $15,25,28,31$ and 22 isolates respectively from varied geographic populations.
Cluster 1 constituted isolates from Kabarole and Namutumba while cluster 4 constituted population of Arua, Iganga, Kumi, Masindi and Pader. Furthermore, clusters 5 and 6 shared nine (9) geographical populations namely; Arua, Pallisa, Kumi, Kabale, Hoima, Masindi, Lira Pader and Serere. But in addition to the aforementioned populations, cluster 6 also Iganga. Lastly, cluster 7 consisted of populations namely; Nebbi, Iganga and Pader.

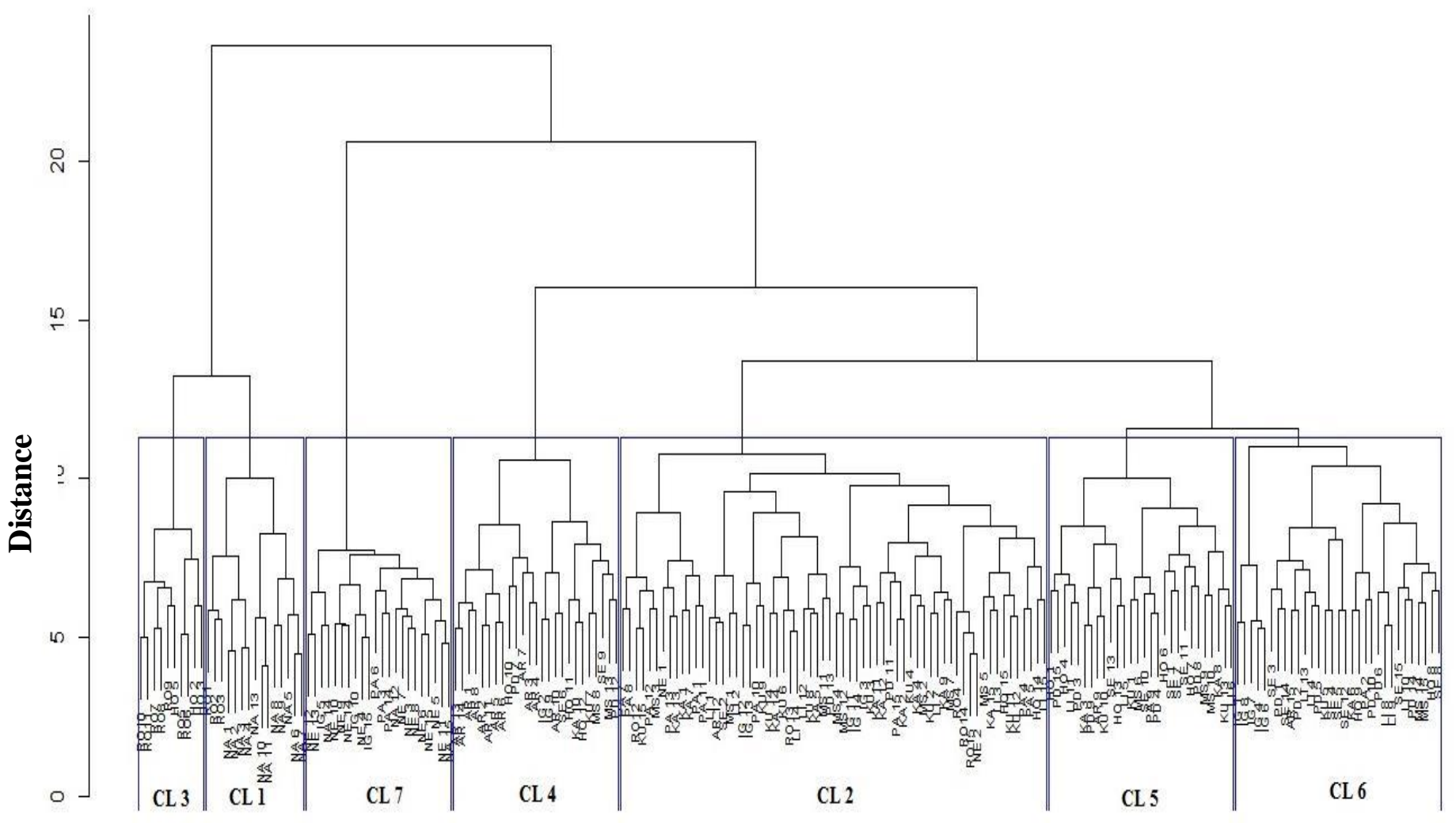

Fig 4: Ward's cluster dendogram of 195 isolates of P. sorghi from 13 different populations in Uganda.

Following cluster analysis and mantel test, Discriminant analysis was carried using the detected number of clusters from the dendogram computed from the Bayesian Information Criterion (BIC, which employs $k$ means) Model to determine whether or not population structure exist within the P. sorghi isolates. DAPC results (Fig. 5) showed genetic variability among the isolates but there was no clear separation pattern among the study population. The results from the DAPC analysis showed no clearly defined population structure and a total of seven discriminant eigenvalues for principal components (PCs) were retained. The proportion of variance conserved by the PCA principal components accounted for $36.9 \%$ variance. Discriminant analysis eigenvalues for PC1, PC2 and PC3 were 40.436, 17.523 and 9.166 respectively. 


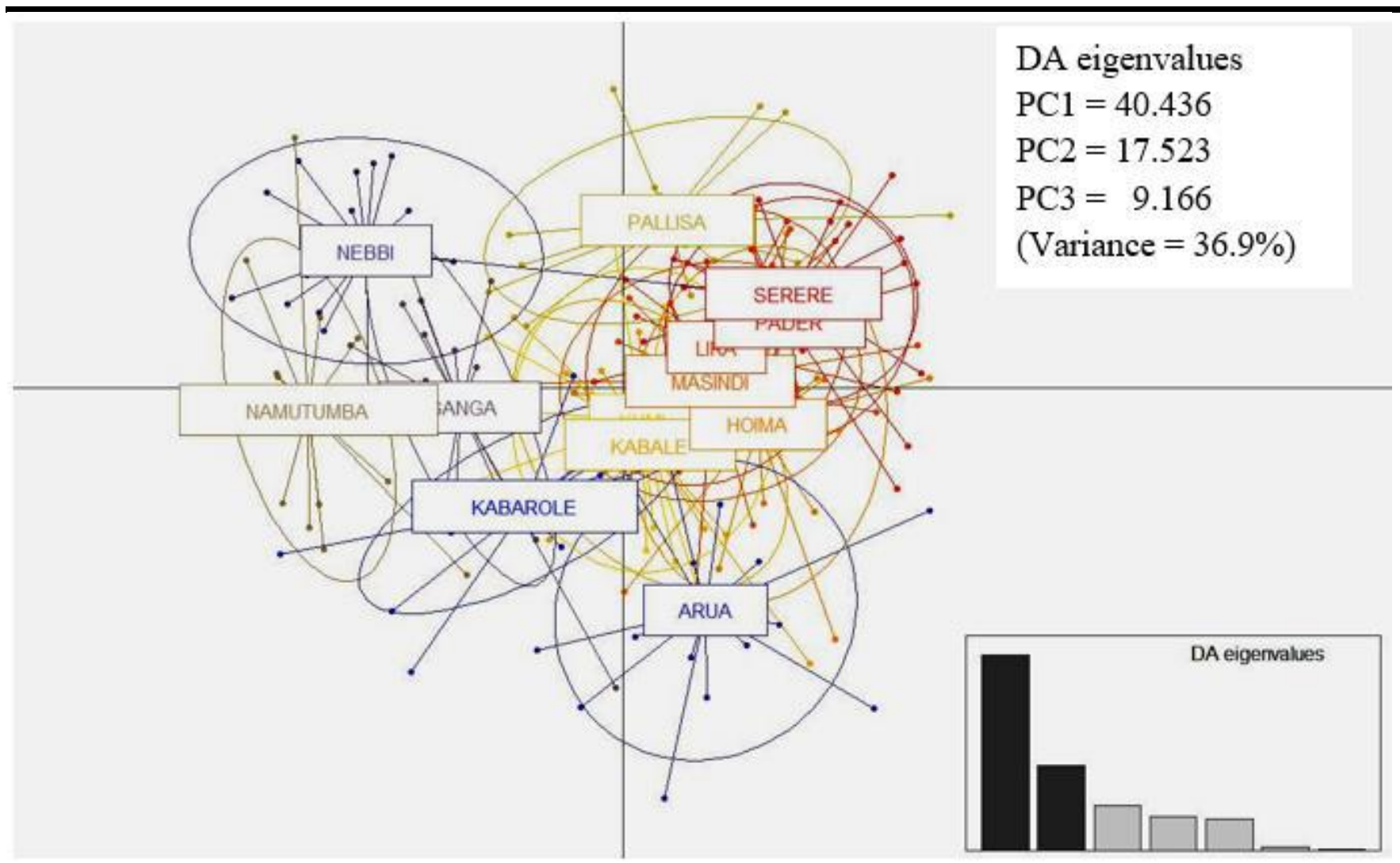

Fig.5: Discriminant analysis of principal components (DAPC) for 195 P. sorghi isolates from Uganda. Each circle represents a cluster and each dot represents an isolate.

\section{DISCUSSION}

Genetic variability is significant to plant breeders for purposes of screening, selection and developing improved crop varieties that confers resistance to biotic stresses and are highly adaptable/ resilient to varied abiotic conditions while offering high quality yield and products for industrial purposes. In this present study, two different primer sets, Random Amplified Microsatellites (RAMs) and Inter-Simple Sequence Repeats (ISSRs) were used to assess genetic divers ity and population structure of $195 \mathrm{P}$. sorghi isolates from 13 different populations in Uganda. The combination of these two molecular markers was effective in evaluating the genetic diversity, population structure and estimating genetic variations.

The observed genetic variation in this study was partitioned within population rather than among population or among regions (Table 3). These results indicate that majority of the genetic differentiation (88.9 $\%)$ existed within the defined population of P. sorghi isolates and among populations $(8.7 \%)$. However, the insignificant genetic differentiation value of $P$. sorghi is olates among regions $(2.7 \%)$ in this study showed that genetic differentiation was independent of the geographic regions (agro-ecological zone) of the isolate. These result agreed with other findings on genetic diversity in $P$. sorghi reported from other parts of the world such as India (Mathiyazhagan et al. 2008; Ladhalakshmi et al., 2009), Indonesia (Lukman et al., 2013) and the United States (Perumal et al., 2008) and Africa (Bock et al., 2000).

Results from this study also showed high percentage of genetic polymorphism $(94.04 \%$ ) (Table 4) which explained the high genetic differentiation observed within the P. sorghi population in the AMOVA results. Similar results were reported by Sireesha \& Velazhahan (2015) and Perumal et al., (2008) who reported high genetic polymorphism in $P$. sorghi isolates from sorghum. In addition, Sireesha \& Velazhahan (2015) reported high percentage polymorphic values for $P$. sorghi in sorghum which confirmed the high genetic variations observed in this study. High polymorphic percentage values recorded in this study (Table 4) further confirmed similar findings by Perumal et al., (2008) and (Mathiyazhagan et al., 2008) who also reported high percentage polymorphism (33\%-100\%) in P. sorghi isolates.

Low genetic diversity index (0.304) (Table 4) and high genetic similarity $(98.7 \%$ ) (Table 5) values recorded in this study was not surprising because $P$. sorghi is reported to exhibit high sexual recombination (Heffer-Link et al., 2002) and therefore explained the high level of inbreeding. Another contributing factor 
could be exchange of $P$. sorghi infected sorghum seeds among farmers for cultivation and thereby perpetuating the spread and development of the pathogen (seed-borne). These results were similar to findings of Sireesha \& Velazhahan (2015) and Mathiyazhagan et al., (2008) who reported high genetic simmilarity values of $93 \%$ and 90 $\%$ respectively within $P$. sorghi isolates. Their results further reported low genetic diversity.

Mantel test results between geographic distance and genetic differentiation among the 13 geographic populations of $P$. sorghum revealed no significant correlation (Fig. 3). This result showed that, the observed genetic variability of $P$. sorghi isolates (within population) from the 13 different populations was not structured in geographic space (there is no spatial structure). Cluster analysis result (Fig. 4) revealed that, $P$. sorghi isolates in Uganda could cluster into seven (7) genetically distinct groups according to genetic similarity/identity of the populations. These findings suggested that geographical origin of $P$. sorghi isolates has no influence on the clusters formation.

Discriminate analysis result (Fig. 5) showed no clear well-defined pattern of clusters of genetic structure among the study populations. DAPC analysis therefore confirmed the Mantel test results, that the observed genetic variability of $P$. sorghi isolates within the study populations was not spatially structured.

\section{v. CONCLUSION}

The study revealed a high genetic variation of $P$. sorghi within populations of Sorghi in Uganda. A weak association of genetic isolation by geographic distance was established for $P$. sorghi populations, which suggested that the observed genetic differences of $P$. sorghi was unaffected by the geographical populations. Seven genetically distinct clusters groups were formed from $P$. sorghi isolates according to the genetic similarities.

\section{ACKNOWLEDGEMENTS}

This research was funded by Carnegie Cooperation of New York through the Regional Universities Forum for Capacity Building in Agriculture (RUFORUM). Allan Male's immense technical assistance is gratefully acknowledged.

\section{REFERENCES}

[1] Akogul, S. (2017). An Approach for Determining the Number of Clusters in a Model-Based Cluster Analysis, $\quad(\mathrm{Clc}), \quad 1-15$. https://doi.org/10.3390/e19090452
[2] Bigirwa, G., Adipala, E. and Esele, J. P. (1998). Occurrence of Peronosclerospora sorghi in Uganda. Plant Disease, 82(7):757-760.

[3] Bock, C. H. (1995). Studies of the epidemiology, variability and control of sorghum downy mildew (Peronosclerospora sorghi (Westonand Uppal) C.G. Shaw) on sorghum and maize in Africa. $\mathrm{PhD}$ thesis, University of Reading, UK.

[4] Bock, C. H, Jeger M. J., Mughogho, L. K., Mtisi, E., and Cardwell, K. F. (1998). Production of conidia by Peronosclerospora sorghi on sorghum crops in Zimbabwe. Plant Pathology, 47(3):243-251.

[5] Bock, C. H., Jeger M. J., Mughogho, L. K., Cardwell, K. F., Mtisi, E., Kaula G. and Mukansabimana, D. (2000). Variability of Peronosclerospora sorghi isolates from different geographic locations and hosts in Africa. Mycol Res 104:61-68.

[6] Crow, J. F., Dove, W. F., Hardy, G. H., Equilibrium, H. W., and Edwards, A. W. F. (2008). Anecdotal, Historical and Critical Commentaries on Genetics, 1150(July), 1143-1150.

[7] Excoffier, L., Smouse, P. E., and Quattro, J. M. (1992). Analysis of molecular variance inferred from metric distances among DNA haplotypes: Application to human mitochondrial DNA restriction data. Genetics, 131(2), 479-491. https://doi.org/10.1007/s00424-009-0730-7

[8] Frank, K., Symphorien, A., Arfang, B., Thomas, O., Richard, E., Mildred, O.-S., ... Patrick, R. (2018). Incidence and Distribution of Downy Mildew Disease (Peronosclerospora Sorghi) of Sorghum in Uganda. Int. J. Adv. Res, 6(5), 2320-5407. https://doi.org/10.21474/IJAR01/7117

[9] Frederiksen, R. A, (1980). Sorghum downy mildew in the United States: overview and outlook. Plant Disease, 64(10):903-908

[10] Heffer-Link, V., M. L. Powelson, and K. B. Johnson. (2002). Oomycetes. The Plant Health Instructor. DOI: 10.1094/PHI-I-2002-0225-01

[11] Jeger M. J, Gilijamsea E, Bock C. H, Frinkinga H. D. (1998). The epidemiology, variability and control of the downy mildews of pearl millet and sorghum, with particular reference to Africa. Plant Pathology, 47:544-569.

[12] Jombart, T., Devillard, S., Balloux, F., Falush, D., Stephens, M., Pritchard, J., ... Nei, M. (2010). Discriminant analysis of principal components: a new method for the analysis of genetically structured populations. BMC Genetics, 11(1), 94. https://doi.org/10.1186/1471-2156-11-94

[13] Lachenbruch P. A \& Goldstein, M. (1979). t A nallysis, 35(1), 69-85. 
[14] Ladhalakshmi, D., Vijayasamundees wari, A., Paranidharan, V., Samiyappan, R., \& Velazhahan, R. (2009). Molecular identification of isolates of Peronosclerospora sorghi from maize using PCRbased SCAR marker. World Journal of Microbiology and Biotechnology, 25(12), 21292135. https://doi.org/10.1007/s 11274-009-0117-0

[15] Lukman, R., Afifuddin, A. and Lubberstedt, T. (2013). Unraveling the genetic diversity of maize downy mildew in Indonesia. J. Plant Pathol. Microb. 4: 162 .

[16] Maechler, M., Rousseeuw, P., Struyf, A., Hubert, M., Hornik, K., Studer, M. and P. Roudier. (2016). Package 'cluster'. p.328

[17] Mathiyazhagan, S., Karthikeyan, M., and Sandosskumar, R. (2008). Archives Of Phytopathology And Plant Protection Analysis of variability among the isolates of Peronosclerospora sorghi from sorghum and cornbased on restriction fragment length polymorphismof ITS region of ribosomal. Archives Of Phytopathology And Plant Protection, $37-41$. https://doi.org/10.1080/03235400600628062

[18] Nei, M. (1972). Genetic distances between populations. American Naturalist. 106: 283-292.

[19] Peakall, R. and Smouse P.E. (2006) GENALEX 6: genetic analysis in Excel. Population genetic software for teaching and research. Molecular Ecology Notes. 6, 288-295.

[20] Peakall, R., \& Smouse, P. E. (2012). GenALEx 6.5: Genetic analysis in Excel. Population genetic software for teaching and research-an update. Bioinformatics, 28(19), 2537-2539. https://doi.org/10.1093/bioinformatics/bts 460

[21] Perumal, R., Nimmakayala, P., Erattaimuthu, S. R., No, E. G., Reddy, U. K., Prom, L. K., ... Magill, C. W. (2008). Simple sequence repeat markers useful for sorghum downy mildew (Peronosclerospora sorghi) and related species. BMC Genetics, 9, 1-14. https://doi.org/10.1186/1471-2156-9-77.

[22] Perumal, R., Isakeit, T., Menz, M., Katile, S., No, E.G. and Magill, C.W. (2006). Characterization and genetic distance analysis of isolates of Peronosclerospora sorghi using AFLP fingerprinting. Mycol. Res. 110: 471-478.

[23] R Core Team (2013). R: A language and environment for statistical computing. R Foundation for Statistical Computing, Vienna, Austria. URL http://www.R-project.org/.

[24] Reyes-Valdés, M. H., Santacruz-Varela, A., Martínez, O., Simpson, J., Hayano-Kanashiro, C. and Cortés-Romero, C. (2013). Analysis and optimization of bulk DNA sampling with binary scoring for germplasm characterization. PLoS ONE, 8(11), e79936, 1-8. doi:10.1371/journal.pone.0079936

[25] Reynolds, D. (1992). Gaussian Mixture Models *, (2), 1-5.

[26] Santacruz-varela, A., Marti, O., Simpson, J., Reyesvalde, M. H., Hayano-kanashiro, C., \& Corte, C. (2013). Analysis and Optimization of Bulk DNA Sampling with Binary Scoring for Germplasm Characterization, $8(11)$. https://doi.org/10.1371/journal.pone.0079936

[27] Sireesha, Y., \& Velazhahan, R. (2015). Assessing genetic diversity in Peronosclerospora sorghi causing downy mildew on maize and sorghum, 68(1), 73-77.

[28] Spellerberg, I. A. N. F., \& Fedor, P. J. (2003). E c o $\log$ i c a 1 s o u n d in g: A tribute to Claude Shannon ( 1916 - 2001 ) and a plea for more rigorous use of species richness, species diversity and the 'Shannon - Wiener' Index, 177-179.

[29] Taylor, P. (2012). Journal of the American Statistical Association, (May 2013), 37-41.

[30] Teixeira, H., Rodríguez-Echeverría, S., \& Nabais, C. (2014). Genetic diversity and differentiation of Juniperus thurifera in Spain and Morocco as determined by SSR. PLoS ONE, 9(2). https://doi.org/10.1371/journal.pone.0088996

[31] Wang, M. L., Ryley, M. and Meinke, H, (2000). Prediction of sorghum downy mildew risk in Australia using daily weather data. Australasian Plant Pathology, 29(2):108-119.

[32] Williams, R. J. (1984). Downy mildews of tropical cereals. In: Ingrams DS, Williams $\mathrm{PH}$ (eds) Advances in plant pathology, vol 2. Academic press, London, pp 1-103. 